\title{
X-43D CONCEPTUAL DESIGN AND FEASIBILITY STUDY
}

\author{
Donald B. Johnson* \\ The Boeing Company, St. Louis, Missouri, 63166 \\ Jeffrey S. Robinson ${ }^{\dagger}$ \\ NASA Langley Research Center, Hampton, Virginia, 23681
}

\begin{abstract}
NASA's Next Generation Launch Technology (NGLT) Program, in conjunction with the office of the Director of Defense Research and Engineering (DDR\&E), developed an integrated hypersonic technology demonstration roadmap. This roadmap is an integral part of the National Aerospace Initiative (NAI), a multi-year, multi-agency cooperative effort to invest in and develop, among other things, hypersonic technologies. This roadmap contains key ground and flight demonstrations required along the path to developing a reusable hypersonic space access system. One of the key flight demonstrations required for systems that will operate in the high Mach number regime is the $X-43 D$. As currently conceived, the $\mathrm{X}-43 \mathrm{D}$ is a Mach 15 flight test vehicle that incorporates a hydrogen-fueled scramjet engine. The purpose of the $\mathrm{X}-43 \mathrm{D}$ is to gather high Mach number flight environment and engine operability information which is difficult, if not impossible, to gather on the ground. During 2003, the NGLT Future Hypersonic Flight Demonstration Office initiated a feasibility study on the X-43D. The objective of the study was to develop a baseline conceptual design, assess its performance, and identify the key technical issues. The study also produced a baseline program plan, schedule, and cost, along with a list of key programmatic risks.
\end{abstract}

\section{Nomenclature}

AETB = Alumina Enhanced Thermal Barrier

$A M L=$ Adaptive Modeling Language

GITU = GPS Integrated Tracking Unit

GPS = Global Positioning System

L.E. $\quad=$ leading edge

psf $\quad=$ pounds per square foot (dynamic pressure)

SLV = United States Air force, Reentry Systems Launch Program, Space Launch Vehicle

TPS = thermal protection system

$T / M \quad=$ telemetry

\section{Introduction}

$\mathrm{R}$ esearch into air-breathing hypersonic and related technologies has been conducted by NASA and other agencies for over 50 years which included engine and airframe materials, propulsion physics, aerodynamics and aerothermodynamics, propulsion airframe integration (PAI), vehicle design and systems analysis. In the past 15 years alone, NASA and the Department of Defense (DOD) spent over \$3 billion to advance hypersonic technologies. ${ }^{\mathrm{i}}$. During the late 80's and early 90's, NASA focused on the National Aerospace Plane (NASP), as envisioned by President Reagan. NASP was to be the culmination of years of research in a prototype hypersonic vehicle. However, technology development and manufacturing issues increased program cost, and while significant research and advancements were made during NASP, no system was developed.

\footnotetext{
* Principal Engineer, Boeing Phantom Works, S245-4055, Associate Fellow AIAA.

${ }^{\dagger}$ Engineer, Vehicle Analysis Branch NASA Langley Research Center, M/S 451, Member AIAA.
} 
Since NASP, NASA has continued to invest and perform research in hypersonics. In the early to mid-90's, NASA's Access to Space study ${ }^{\mathrm{ii}}$ continued to evolve hypersonic system designs and derive technology requirements. More recently, the Advanced Space Transportation Program (ASTP) at Marshall Space Flight Center (MSFC) invested significant resources in both systems analysis and technology development ${ }^{i i i}$. ASTP developed a Hypersonics Roadmap, shown in Figure 1, that laid out key flight and ground demonstrations required before a large

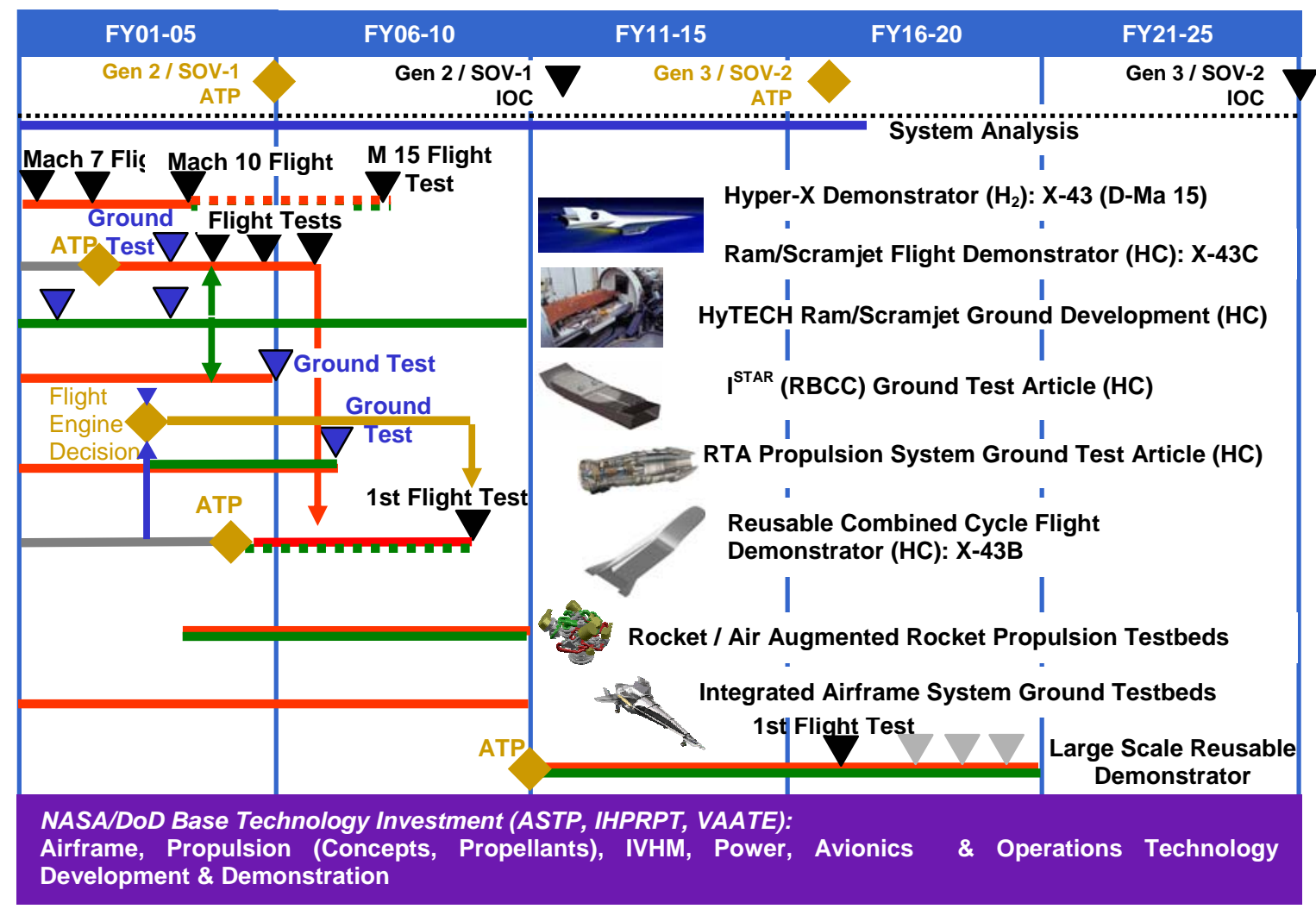

Figure 1.National Hypersonics Roadmap.

scale prototype system could be fielded. While the NASP approach was to develop and apply the technologies required for a hypersonic system into a single vehicle demonstrator, the Hypersonic Roadmap is a stepping stone approach in which technologies are developed and demonstrated in smaller increments. This approach built off of the existing Hyper-X Program ${ }^{\text {iv }}$ which tested at flight conditions of Mach 7 and Mach 10. Flight demonstrators were added that provide testing over a range of Mach numbers in a single flight (e.g., X-43C which accelerates from Mach 5 to Mach 7 under its own power). This would be followed by reusable systems that would fly from subsonic to hypersonic speeds in single tests (e.g, X-43B accelerating from Mach 0.7 to Mach 7). The need for even higher Mach number testing was identified. The X-43D was conceived to test in the Mach 12 to Mach 15 range at single flight conditions, much like Hyper-X (X-43A).

ASTP was absorbed into the Next Generation Launch Technology (NGLT) program, which continued to invest in both advanced rocket (i.e. $2^{\text {nd }}$ Generation) and hypersonic ( $3^{\text {rd }}$ Generation) vehicle technologies. Within NGLT, the Future Hypersonic Flight Demonstrators Office was established to oversee development and execution of the flight demonstrators called out in the roadmap. In the spring of 2003, this office initiated a conceptual design and feasibility study for the X-43D. The goal of the study was to develop a conceptual design for the X-43D and related flight elements in such detail as to identify key technological and programmatic issues and risks while providing enough fidelity to produce a reasonably accurate program cost estimate. Langley's Vehicle Analysis Branch lead the study and Boeing's Phantom Works was contracted to assist. In addition to leading the study, Langley was responsible for the engine keel line and propulsion database development, vehicle outer mold line (OML), structural analysis, aerodynamic, thermal, and CFD support. Three Boeing sites were involved: Huntington Beach provided TPS sizing and structural analysis; Rocketdyne (Canoga Park) provided fuel system design, engine structural and thermal analysis; and St. Louis which lead the Boeing effort while providing vehicle weights, packaging, 
aerodynamics, trajectory and performance, boost trajectory analyses, program schedule and cost. Two design iterations were completed, but only the highlights of each are discussed.

\section{Research Vehicle Conceptual Design}

The vehicle design started with the mission definition: accelerate at Mach 15 with a powered (fuel on) test time requirement of 30 seconds. Acceleration at Mach 15 with a demonstrator vehicle was expected so be a significant challenge given the effects of scale on engine performance, the fact that total temperature limits are being approached at Mach 15, and that airframe material choices would likely be metallics (vs. composites on an operational system) making the vehicle heavier than a flight-weight prototype would be. While lower Mach numbers are of interest to the program, it was decided to assess the capabilities at the most challenging condition first and evaluate the results there. A vehicle length of 20 feet was selected based on previous work and experience. A 2-D (two-dimensional) keel line was designed using SRGULL ${ }^{v}$ within an AML ${ }^{v i, v i i}$ design environment. The engine was designed to be oversped (i.e. the bow shock from the vehicle nose would lie inside the engine). Other design considerations included the need to limit shock strength by reducing forebody flow turning while keeping enough compression for good thrust. Flow dissociation was also an issue, and the internal flowpath geometry was modified to reduce or eliminate this problem. Engine width was maximized in order to capture as much of the incoming air compressed by the forebody as possible. And the nozzle design was adjusted to maximize axial thrust while keeping flow separation, vehicle moments and trim in mind. After the keel line was complete, a propulsion database was generated covering multiple Mach numbers, vehicle angles of attack, dynamic pressures, and fuel equivalence ratios. A cowl to tail (CTT) aero/propulsion accounting system was followed to track all of the vehicle forces and moments. This accounting scheme is depicted in Figure 2.

Once the keel line was complete, the lines were lofted using Pro-Engineer to create a 3-D (three-dimensional) OML, as shown in Figure 3. Experience from previous demonstrator programs and systems analyses helped to set the upper surface initial angle, as well as to size the all-moving horizontal tails (AMHT) and vertical tails. Ventral surfaces were added as a result of experience from the X-43C. These surfaces keep the expanding engine exhaust plume from spilling onto the AMHT surfaces which helps engine performance, minimizes potential heating issues on the AHMTs and reduces design complexity by separating the aerodynamic and propulsive surfaces. The ventrals and vertical tails also provide a wiping surface for the AMHTs and were sized and shaped to provide adequate AMHT deflection range without unport. Multiple versions of the OML were generated for use with different analysis tools. In addition to sharp versions with the engine cowl open and closed (all leading edges are sharp, i.e. come to a single point), blunt versions were also created for CFD analysis. Preliminary aerodynamic and thermal analysis was performed on the vehicle for various leading edge radii. Comparisons showed that, at the same radius, the heat load seen by the $65^{\circ}$ swept leading edges of the AMHTs on the X-43D would be similar to that experienced by the vehicle nose leading edge on the Mach 10 Hyper-X flight, and therefore would not need active cooling. However, it was also determined that the X-43D nose leading edge and engine leading edges would have to be actively cooled, so their radii were set by manufacturability limits. The control surface leading edge radii were arrived at by a trade between their ability to be passively cooled and their drag effects on the vehicle. Smaller leading edge radii reduce vehicle drag, but are increasingly difficult to manufacture and to keep cool (or from melting), while the reverse is true for larger leading edge radii. Following this preliminary analysis, materials experts were consulted and the leading edge radii were selected for the horizontal and vertical control surfaces, vehicle nose, and engine components (cowl, sidewalls, splitters).

The vehicle OML was passed to the structures discipline which sized and laid out an initial structural arrangement. This arrangement was given to packaging and weights experts who sized, fit, and packaged all of the necessary systems (many of which are heritage X-43A systems) into the vehicle, as shown in Figure 4 . The propulsion systems team selected a blowdown fuel delivery system as a baseline because of its simplicity. (Analysis supporting this decision is discussed later.) The propulsion team provided initial estimates of required fuel flow rates and pressures, as well as fuel amount required. The packaging engineer used these estimates to size the fuel and pressurant tanks accordingly. The propulsion team also decided to size a silane tank for ignition based upon the same methodology used for X-43A. While the team agreed that silane would probably not be required for ignition at these flight conditions, the tank was retained for possible use for flame-holding or piloting, which will be examined in the future. If not required, the silane could be swapped for additional coolant or fuel. 


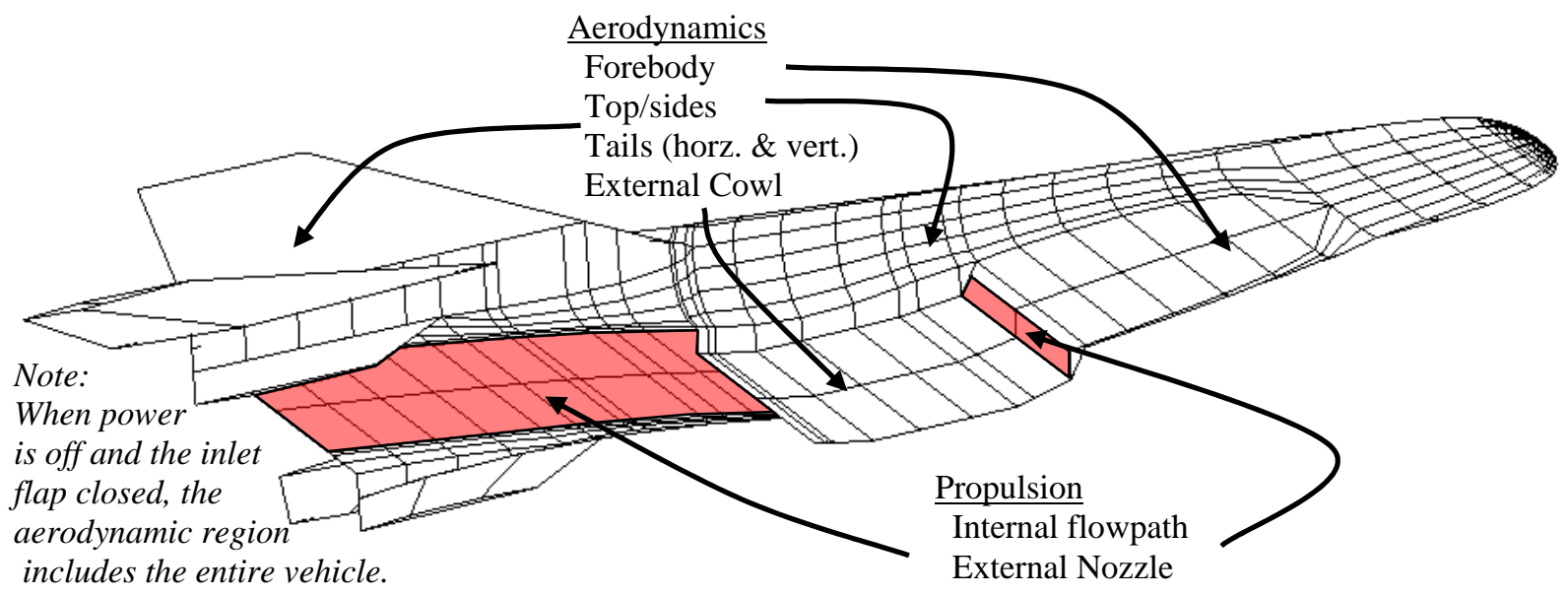

Figure 2. Cowl to Tail (CTT) force accounting system description.

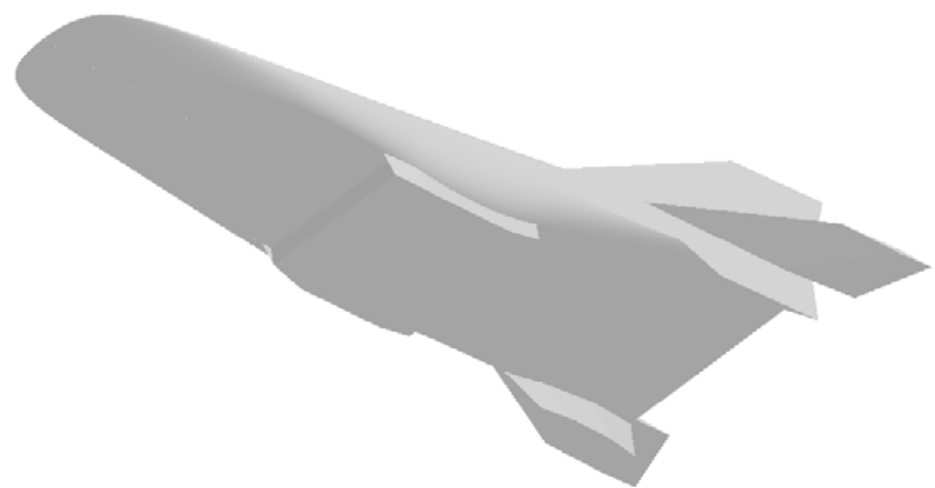

Figure 3.Isometric view of X-43D vehicle.

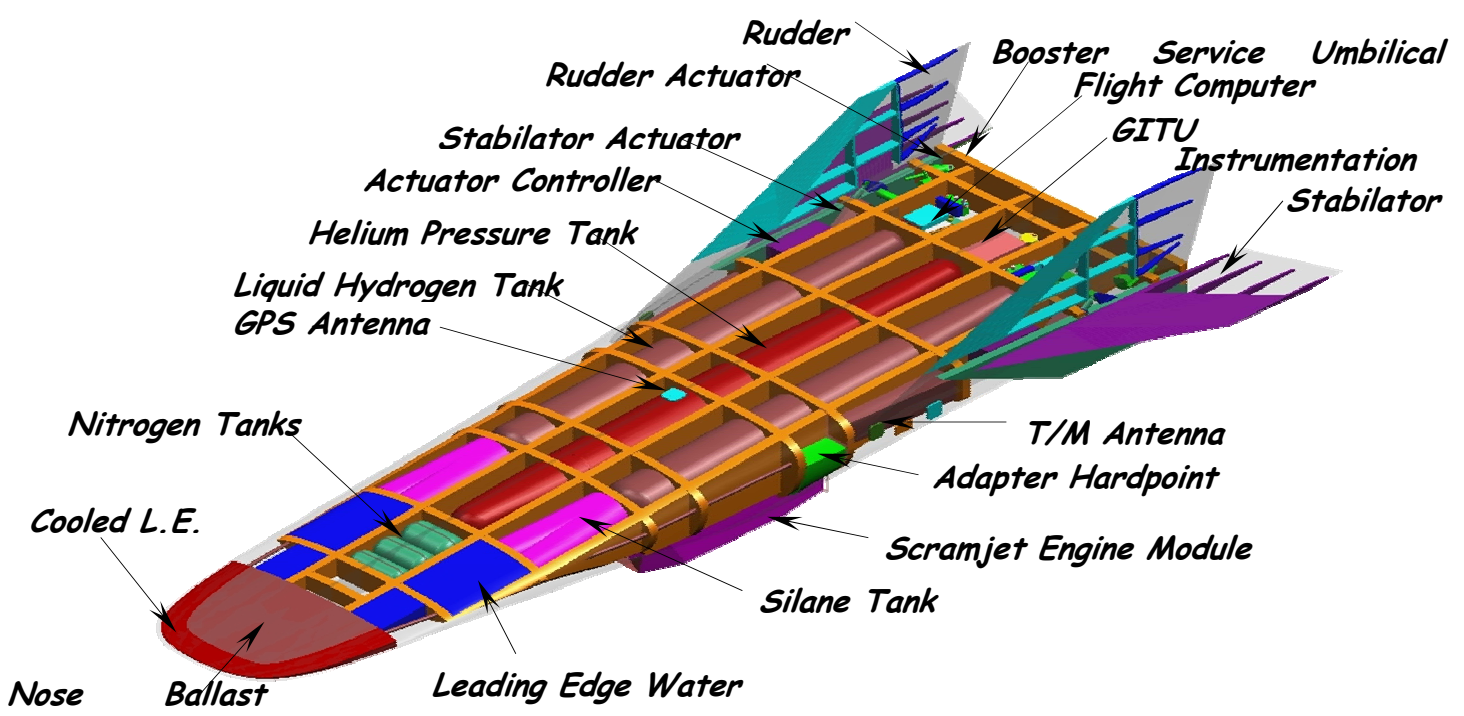

Figure 4. Internal packaging / layout of X-43D.

American Institute of Aeronautics and Astronautics 
Once the systems were packaged, a vehicle weight statement was generated. To reduce system design complexity, a ground rule was established that called for the vehicle to be statically stable in the longitudinal axis. This meant that the tungsten ballast in the vehicle's nose had to be sized to provide the vehicle with a more forward center of gravity (c.g.) location. Initially, a 50\% (of vehicle length) c.g. location was chosen (to be validated later by aerodynamic analysis). Aluminum-lithium was chosen for the airframe structure and graphite composite was assumed for the tanks. The horizontal and vertical tails are TPS covered titanium-aluminum with carbon-carbon leading edges. The final vehicle weight statement, including a $10 \%$ margin on empty weight, has a dry weight of about $5,300 \mathrm{lbs}$ and a gross weight of about $5,700 \mathrm{lbs}$. Of this, $1 \%$ is useable liquid hydrogen fuel , $1 \%$ is useable helium pressurant, and $3 \%$ is useable water for cooling the nose leading edge.

The vehicle OML was also passed to the aerodynamics discipline for development of the aero database. Engineering-level methods were used to generate drag, lift and moment data for the portions of the vehicle book kept under aero. Total airframe drag was calculated using a component buildup method which included pressure, base, viscous and leading edge drag. The base drag was estimated using a correlation for slender body shapes. Viscous drag was calculated using a modified, flat-plate method and the leading edge drag was calculated based upon Newtonian flow at freestream conditions. Lift, drag, and pitching moment were calculated at three Mach numbers (14, $15 \& 16)$, and for a range of angles of attack and AMHT deflections.

The aero team initially assumed the vehicle to have turbulent flow for conservatism and ease of calculation. After discussion, they reran calculations for transitional flow and found that nearly $95 \%$ of the vehicle would be laminar if the boundary layer were allowed to transition naturally. However, the propulsion team prefers to have turbulent flow entering the engine inlet for better mixing and combustion efficiency. The aero team modeled this effect by assuming $25 \%$ of the vehicle to be turbulent and the rest laminar. The aero team was also responsible for generating aerodynamic heating rates for the thermal team to use in TPS sizing. Heating rates were calculated based upon the radiation equilibrium temperature for a range of flight conditions. Again, for conservatism, the heating rate calculations were based upon a fully turbulent boundary layer for the entire vehicle. A preliminary boost and test trajectory, which will be described later, was also supplied to the thermal team for evaluation. The baseline boost trajectory has a lofted profile, with separation of the research vehicle occurring at $65 \mathrm{psf}$ dynamic pressure. Prior to separation, the vehicle is protected by a shroud. The thermal evaluation therefore starts at separation and included a 70 second, un-powered descent to the test condition as well as the 30 second powered test. The thermal team assumed a TPS stack-up of AETB12 on a strain isolation pad (SIP) on top of an aluminum substructure. TPS tile thickness was sized based upon two constraints: 1 ) the adhesive that holds the tile to the SIP must remain under $550^{\circ} \mathrm{F}$ and 2) the temperature of the aluminum substructure could not exceed $250^{\circ} \mathrm{F}$. Several locations on the vehicle exhibit tile temperatures near or exceeding the maximum use temperature for AETB. This has been flagged as a potential risk, but there are several mitigating actions that have yet to be explored including alternate materials, changing test conditions, and reanalyzing for the actual transitional boundary layer state.

Vehicle performance was calculated using a 3-degree of freedom (3-DoF) trajectory simulation program. The vehicle was flown trimmed in the pitch plane and along a constant dynamic pressure flight profile. Vehicle acceleration was examined over a range of dynamic pressures from 1000 to 2000 pounds per square foot (psf) and was found to be better at higher values. However, vehicle thermal issues are worse at higher dynamic pressures. In the end, the baseline performance was evaluated along a constant 1500 psf dynamic pressure trajectory. The vehicle was determined to have sufficient fuel volume to accelerate during the 30 second powered test, with about $10 \%$ useable reserve. The descent to the test point after booster separation and the descent to splashdown post-engine test are described later as part of the boost trajectory analysis.

Several trade studies were performed during the effort. Two options were considered for the fuel delivery system. A blowdown system was initially selected because of its simplicity and the resulting lower cost and risk. The performance of the blowdown system was analyzed to ensure it could provide fuel at the required flow rate and pressure over the duration of the powered test. Several pump fed systems were also designed and analyzed for comparison including a hydrogen peroxide gas generator (GG) cycle, a liquid hydrogen / gaseous oxygen GG cycle and a liquid hydrogen expander cycle. The primary issues for pump fed systems were the need for new pump designs (cost) and their ground testability (risk). Based on the results of the study, see Figure 5, the blowdown system was retained. 


\begin{tabular}{|c|c|c|c|c|c|}
\hline & \multicolumn{2}{|c|}{ Meet System Requirements } & \multicolumn{3}{|c|}{ Design Issues } \\
\hline Fuel/Cooling System Concepts & Flowrate & Pressure & Weight & Risk & Complexity/Cost \\
\hline Pressure Fed (blowdown) & Yes & Yes & Heaviest & Lowest & Low \\
\hline Pump Driven Systems & & & & & \\
\hline Hydrogen Peroxide Gas Generator & Yes & Yes & $67 \%$ & Lowest Pump & New Pump \\
\hline LH2/GO2 Gas Generator & Yes & Yes & $67 \%$ & Higher Pump Risk & New Pump \\
\hline LH2 Expander Cycle & Yes & Yes & $50 \%$ & Highest Pump & New Pump \\
\hline
\end{tabular}

Figure 5. Summary of Fuel System Trade Study Results

Several trades were performed on the engine structure and mechanical design. The baseline engine was drawn with three equal width engine modules and a single inlet flap for all three modules. Trade studies looked at varying the number (and therefore width) of engine modules as well as a single versus multiple inlet flap configurations. In terms of the overall structural architecture for the engine, the designers considered both ribbed and honeycomb architecture. The ribbed design was selected because it was found to be much simpler from a manufacturing standpoint resulting in lower cost. A finite element model of the integral ribbed design was then developed. Multiple load cases were analyzed, including both thermal and mechanical loads. The response of the structure was observed and the geometry (rib spacing) was adjusted to minimize weight while not exceeding the maximum allowable deflection. Figure 6 shows the engine under $10 \mathrm{~g}$ 's of acceleration load in all three axes. Deflections on the order of 10 mils were observed under these conditions, which are well within the acceptable range. Figure 7 shows exaggerated deflections of the combustor section under $1000^{\circ} \mathrm{F}$ thermal gradient and 20 psi pressure loading. This particular case had rib spacing at 4 inches resulting in a cross sectional area change at the throat of $\sim 11 \%$. This

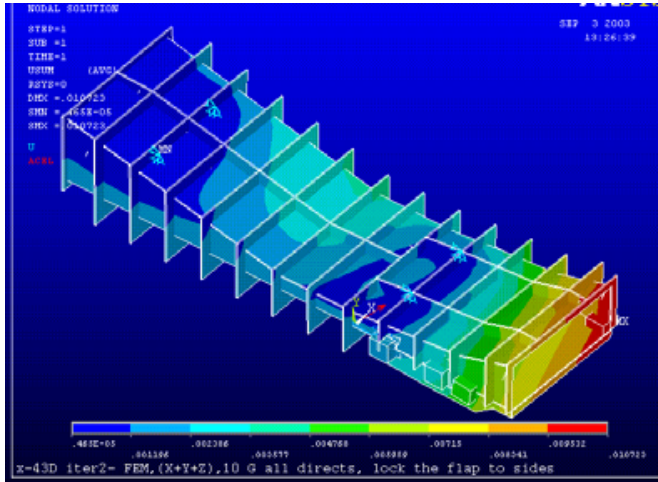

Figure 6. Ribbed engine design under heavy mechanical load.

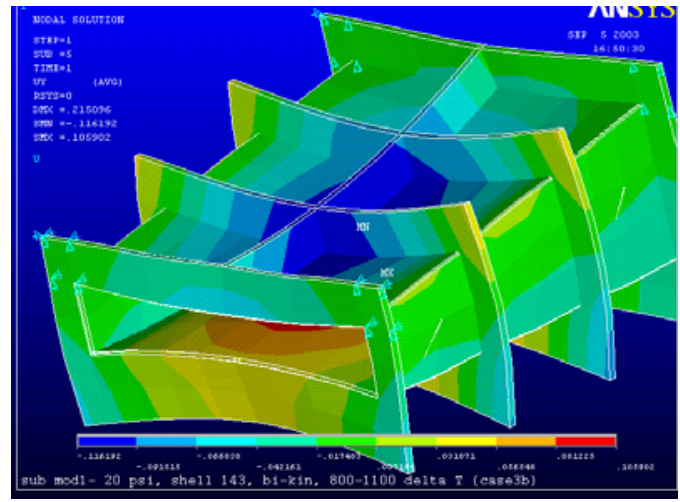

Figure 7. Ribbed engine design under thermal and mechanical load.

did not satisfy our goal to reduce cross sectional area change to $5 \%$ or less. After further analysis, a 1.5” rib spacing was found to meet the deflection requirement and was adopted for the baseline design. The team also determined that structural requirements could be met with the three flowpath / single inlet flap arrangement. The single inlet flap was shown to be feasible and to minimize dynamic seal problems, but requires a larger hinge and thicker cowl than individual flaps.

A trade study was also performed to examine the affects of vehicle fineness ratio on performance and the vehicle's ability to achieve the mission. Here, fineness ratio is defined as the vehicle length divided by the equivalent vehicle diameter at the location of maximum cross sectional area. As mentioned, the baseline vehicle was drawn with a fuselage length of $20 \mathrm{ft}$. It is roughly 70" across (not counting the AMHTs) at the widest point and just over two feet high (not counting the vertical control surfaces). This vehicle has a fineness ratio of about 5.4, which is very close to that of other demonstrator and operational vehicles examined previously by this team ${ }^{\text {viii }}$. However, a flight demonstration concept similar to X-43D, called HyFlite, was proposed during the NASP program 
which had a much higher fineness ratio (approx. 8). Based on the knowledge that cost savings could be realized with a smaller (thinner) vehicle, the team investigated the affects of fineness on the vehicle's ability to accelerate and its ability to perform a 30 second powered test. Two additional vehicle shapes were generated to perform this study. Starting with the baseline vehicle geometry, a wider vehicle with four engine flowpath modules (of the same individual module width as on the baseline) and one with two engine modules were developed. Profile and endview drawings of these two vehicles are depicted in Figure 8 showing the relative width of the vehicles and their common profile shape.
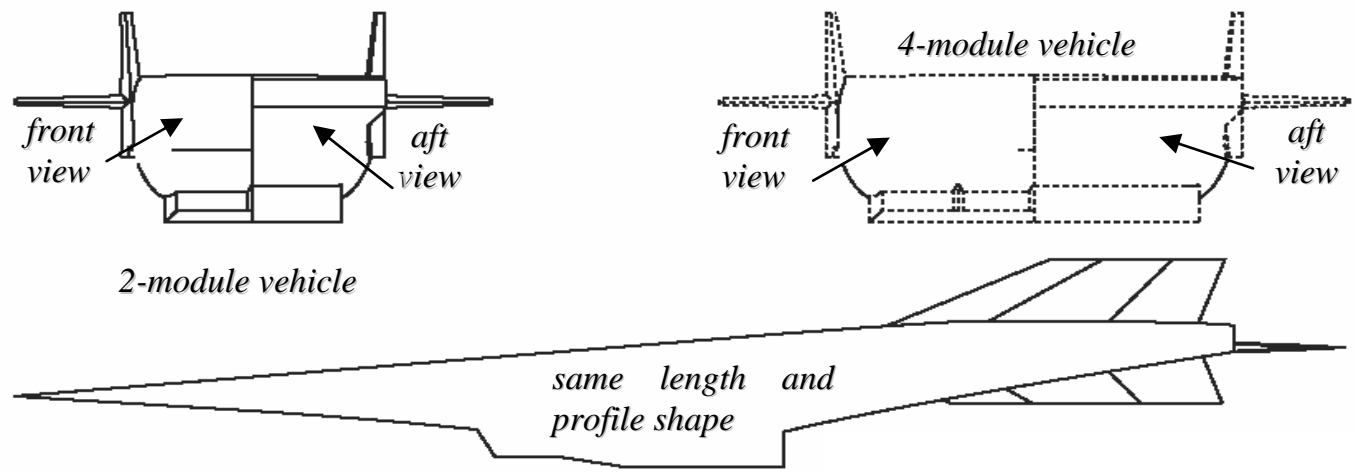

Figure 8. Two and four module vehicles examined in the fineness ratio trade study.

Each vehicle was packaged using the AML design environment, and weight statements were developed (see Figure 9). New aerodynamic and propulsion databases were generated for both shapes, and the performance for each was calculated with 3-DoF trimmed trajectory simulations. Each vehicle was found to have enough fuel to be able to perform the 30 seconds required powered engine test. However, vehicle acceleration was greater for the wider vehicle when compared to the baseline, while the narrower vehicle showed reduced acceleration capability. It will ultimately be necessary to balance system requirements (traceability, engine performance and operability, acceleration, cost, etc.) in selecting the final fineness ratio.

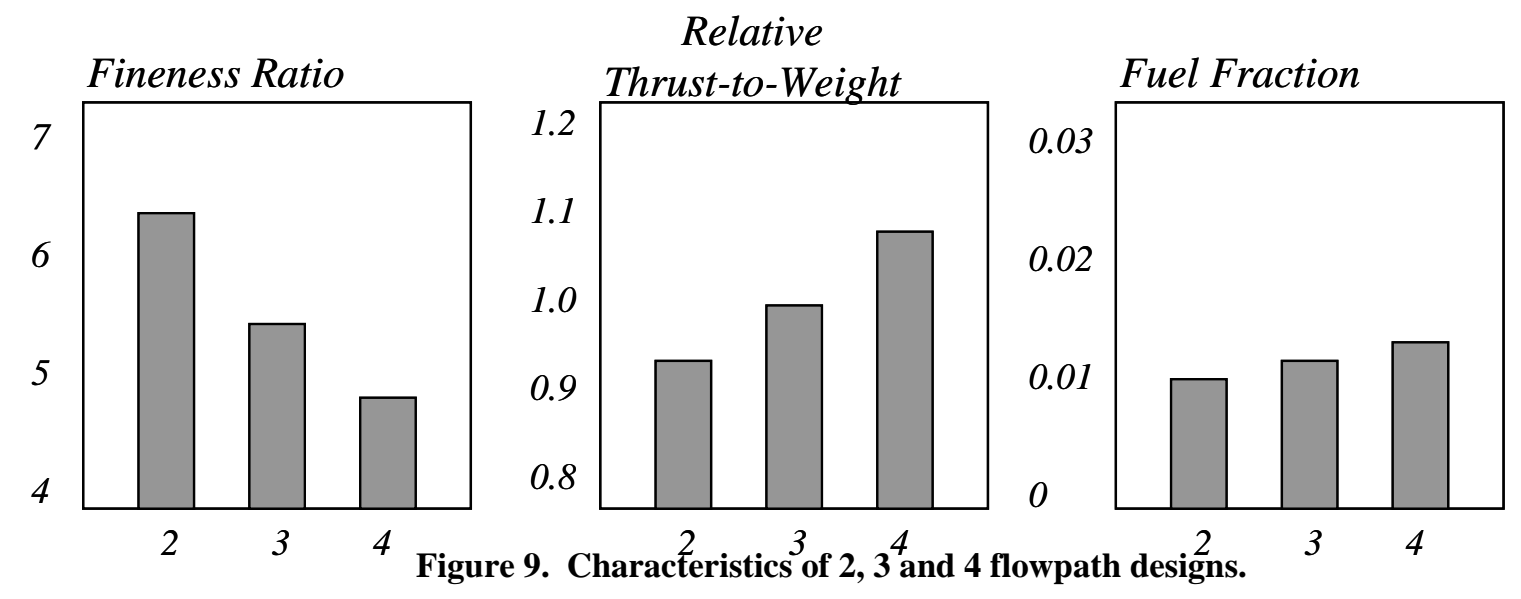

\section{Launch Stack Design and Analysis}

The launch system selected for the X-43D mission is a three-stage Peacekeeper SLV. The first three stages of Peacekeeper are minimally modified from their existing designs (primarily to add range safety equipment). Atop those stages would be a guidance wafer to provide booster control (in its ICBM configuration, guidance commands for the Peacekeeper are provided by the forth stage). This guidance wafer is under development by the Air Force's launch service provider for the Peacekeeper SLV system (Orbital). An adapter to hold the research vehicle would be placed on top of the guidance wafer and a new, two piece shroud would cover the X-43D and attach near the aft end of the adapter. The gross launch weight for the system is estimated at just over 202,000 lbs. The launch configuration is depicted on the left side of Figure 10. The rest of the figure illustrates the baseline trajectory and flight profile. The system would be launched out of Vandenberg Air Force Base (VAFB) on a due west trajectory 
out over the Pacific. The three boost stages would burn out and fall back to the ocean within about 200 nautical miles of the launch site. The shroud would be separated and the research vehicle released at about Mach 16.5 and a dynamic pressure of 80 psf. At that point, water cooling of the vehicle leading edges would begin. The vehicle would descend (and slow) to the test condition, with a pull-up maneuver prior to the test to arrest the dive. The test would occur at Mach 15, and 1500 psf dynamic pressure. After the 30 second engine experiment, the vehicle would then descend and splash into the Pacific, roughly 1,300 nautical miles downrange from VAFB.

As indicated in Figure 10, alternate, direct ascent boost profiles were examined for a range of test conditions (1,000 to 2,000 psf at Mach 15) as well as higher lofted (separation near 0 psf) trajectory cases. Other launch systems were also analyzed including the Athena II, Delta IV, and Sea Launch. The capabilities of each system were analyzed for each of the mission profiles. The direct ascent approach proved to have a number of issues including stability and control of the stack, extreme q*alpha loads, and marginal performance to Mach 15 conditions

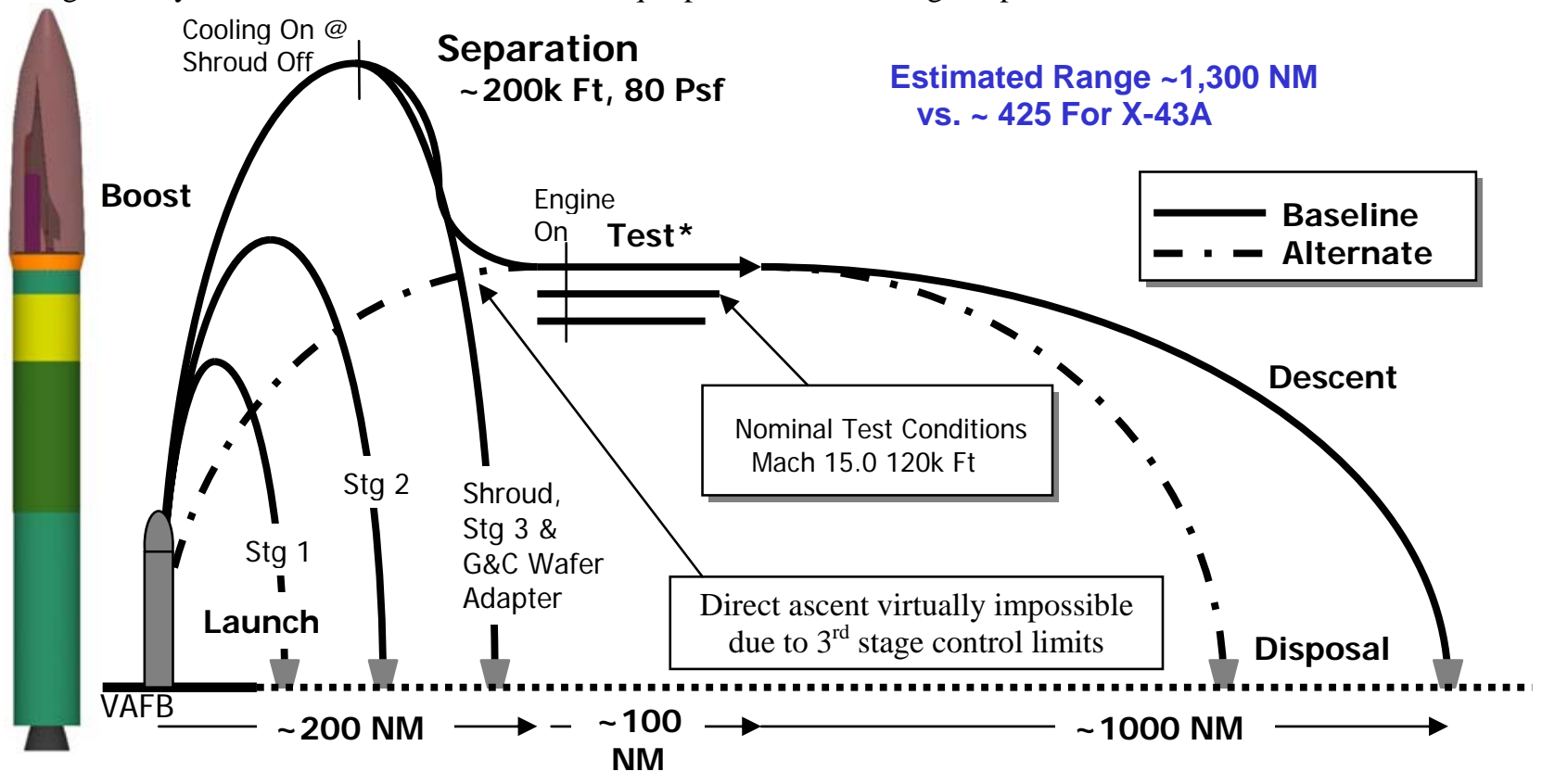

Figure 10. Baseline launch scenario and stack configuration.

due to high drag losses. This led to selection of the lofted approach. Of the four launchers, the Peacekeeper performed slightly better to the lofted conditions, though the others were close. Beyond its performance, however, the cost of the Peacekeeper is substantially lower than the others and it was selected as the baseline launch system. Separation was selected to be at or near 80 psf. This condition allows aerodynamic control of the research vehicle as it separates from the booster, something that would not be possible if separating near 0 psf.

Range safety analysis of the boost trajectory indicated potential issues with the flight termination system (FTS) which would be required for this mission. Trajectory analysis shows that the X-43D flies a significant distance downrange (over the horizon from the range safety site which controls the FTS). To reach the vehicle, command signals to the onboard FTS would have to be relayed, a procedure which is currently not allowed. In addition, the frequency currently used for FTS signals is seriously attenuated by the plasma environment the vehicle operates in. contact at hypersonic speeds may require new hardware at the range safety site, support aircraft/ships.

Additional, detailed analysis of the launch stack was conducted. Aerodynamic data were initially generated based upon Missile DATCOM for each of the staging configurations. A weight statement was generated and a more detailed trajectory analysis was performed. Stability and control assessments of the launch stack in each of its staged configurations was also performed. The aero team was concerned that the new "hammerhead" shroud required to house the research vehicle might be too large for the launch system to handle. Using the Missile DATCOM aero database, stack stability was evaluated by quantifying the static margin at two degrees angle of attack.. The static margin was found to be on the same order as that for the standard Peacekeeper launcher for each of its staging configurations. Vehicle control was analyzed by comparing the aerodynamic moment generated by the 
launch stack to the potential propulsive moment that could be obtained from the thrust vectoring nozzles. This assessment was performed at numerous points along the baseline boost trajectory. The analysis showed that for the baseline lofted profile, vehicle control would not be an issue. At the most marginal points in the flight, the potential propulsive moment was found to be an order of magnitude more than the aerodynamic moments generated by the stack.

This analysis, however, was based upon low fidelity aerodynamic data. The aero team felt that higher order methods (CFD) should be brought to bear on the problem to confirm the preliminary results. Five flight conditions

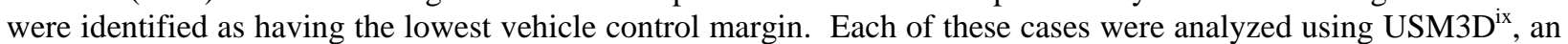
unstructured 3-dimensional Navier-Stokes CFD code. Figure 11 shows Mach contours of the stack in its three stage configuration at four degrees angle of attack (AoA) and Mach 1.2 freestream conditions. Figure 12 shows similar results at Mach 3.0 and four degrees AoA. The other cases analyzed were Mach 0.3 at $15^{\circ}$ AoA (full stack), Mach 1.5 at $4^{\circ}$ AoA (full stack) and Mach 5 at $4^{\circ}$ AoA (2-stage config.). Aerodynamic moments were calculated at these conditions and compared to the results generated by Missile DATCOM. Although somewhat different than the DATCOM data, the CFD results still indicated that there were no issues with vehicle control.

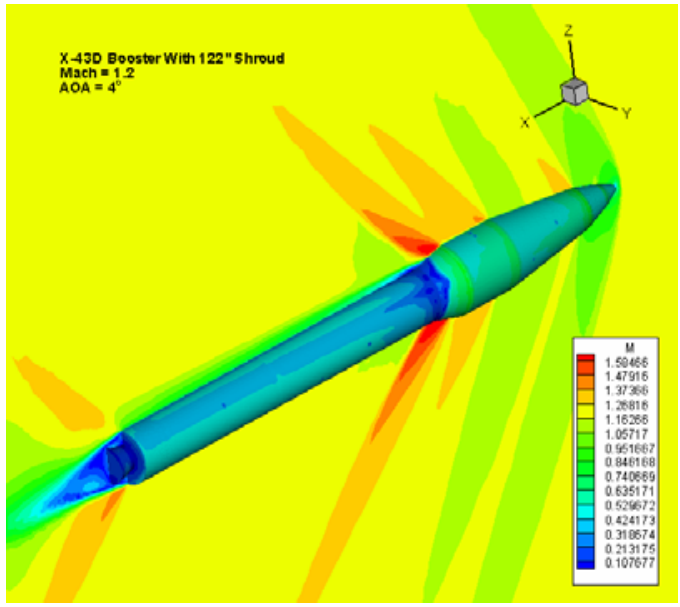

Figure 11.Mach contours on launch stack from USM3F CFD solution (Mach 1.2, freestream).

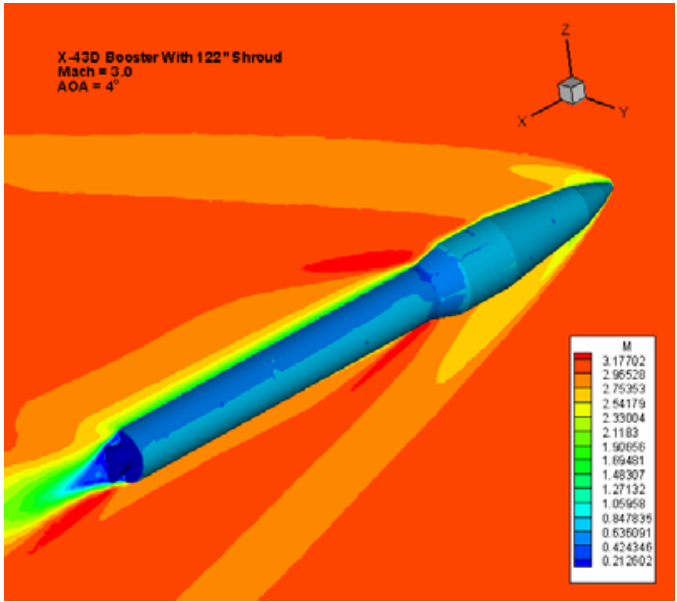

Figure 12.Mach contours on launch stack from USM3D solution (Mach 3, freestream).

The structures team spent significant effort trying to analyze the structural frequency and bending modes of the launch stack. It is important to characterize the structural modes of the launch stack so that they don't interfere with the flight control system. One of the lessons learned from the X-43A program was that the launch stack $1^{\text {st }}$ bending frequency in both the pitch and yaw planes was very difficult to raise to the required level set by the flight controls. On X-43A, the key structural element is the adapter that attaches the research vehicle to the launcher. The design of the adapter structure and its load paths, as well as the placement of the attachment points on the research vehicle are critical factors in being able to modify the system's structural modes. For this effort, the structures team developed and analyzed several adapter designs and attachment schemes. Adapter structural concepts included a simple truss that supported the research vehicle from the base of the adapter through a vehicle bulkhead attachment near the aft of the engine. A second concept used more of a tubular shape in the adapter structure which helped to provide torsional resistance in addition to bending in the pitch and yaw axes. This concept also attached to a bulkhead near the aft end of the engine. Ultimately, a version of the second concept was chosen as the baseline adapter concept. Finite element models of the research vehicle and adapter were generated. Ideally, the structures team would have liked to analyze the entire launch stack but sufficient data was not available on the Peacekeeper. During X-43A, bending analysis was performed on two versions of the launch stack, one that included all of the elements (referred to as the full stack) and one with only the research vehicle and adapter (referred to as the short stack). The structures team learned that the biggest issues with the stack frequency could be solved by analyzing and optimizing the short stack, which is what was done here.

With finite element models of the research vehicle and adapter in hand, load cases were identified along the baseline boost and free flight trajectories. Inertial loads from the trajectory were applied in each of the load cases 
and the corresponding flight conditions were used in conjunction with the aerodynamic database to apply surface pressures to the model. In total, 1125 cases were analyzed using NASTRAN SOL-200. The structures team found that 19 of the cases actually enveloped the entire design space. Figure 13 shows the aerodynamic pressure distribution applied to the research vehicle for one of the load cases. Figure 14 shows the $1^{\text {st }}$ bending modeshape with colors indicating points of highest strain energy density. Through structural optimization, the structures team determined that the short stack $1^{\text {st }}$ bending mode frequency could be improved from $7.5 \mathrm{~Hz}$ to $10 \mathrm{~Hz}$ through thickening of the skins on the research vehicle. However, this came at a fairly sizeable weight penalty. In the end, the structures team recommended that the vehicle structure be sized not to meet frequency requirements, but for strength, buckling, and closed loop control system stability margin.

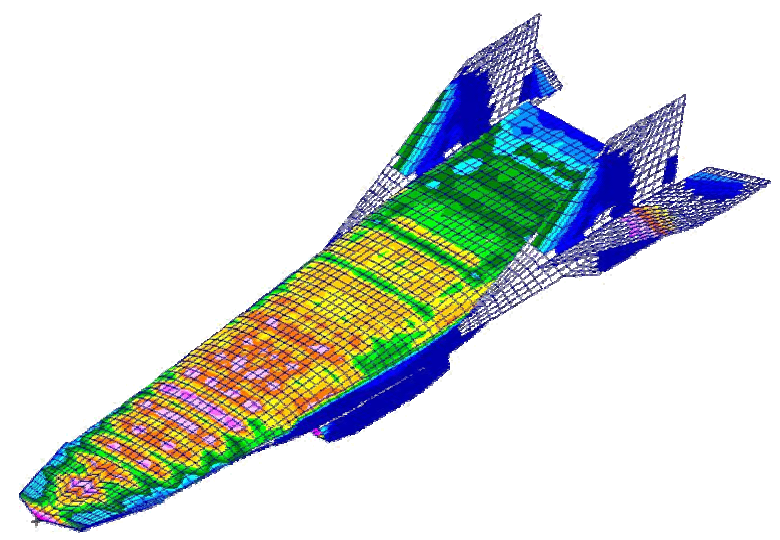

Figure 13. Pressure loads applied to structural Model.

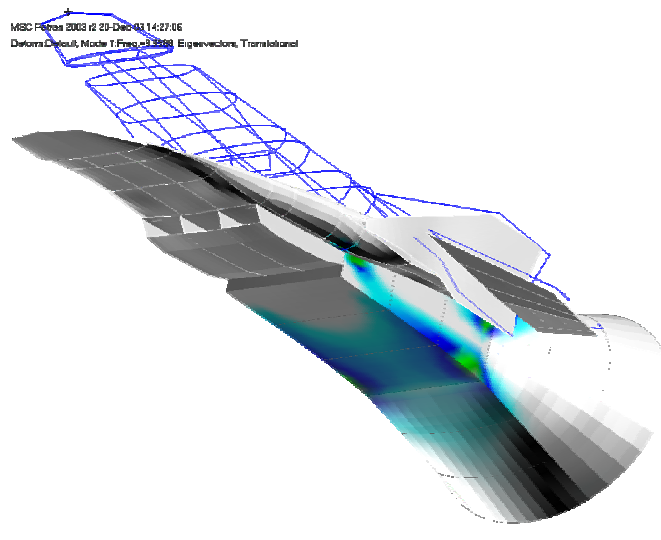

Figure 14. Structural frequency and bending Analyzed.

\section{Programmatic Analysis}

In addition to the technical work performed for this study, the Boeing led the team in performing programmatic analyses. A detailed three level work breakdown structure (WBS) containing over 200 elements was created. While there were multiple ways to organize the WBS (e.g. along disciplines or by hardware elements), organization along hardware elements was chosen because that format could be more easily related to procurement cost. There were seven main elements in the WBS, including a project management function, the X-43D research vehicle, the launch system, logistics, system test and evaluation, verification and validation, and flight operations. A program plan with key milestones was established and all data was rolled into Microsoft Project ${ }^{\circledR}$ to create an overall program schedule, shown in Figure 15. As shown, the program start date was assumed to be the start of FY05 with the first flight occurring four years later with flights recurring every 12 months thereafter over the three flight program.

Boeing used this information to develop a detailed cost estimate. Boeing assumed that the work split would be similar to that in the X-43A program. This meant that there was significant NASA in-house analysis in support of the development and verification of the design. Government furnished items, as in X-43A, would include wind tunnel testing, flight operations, ground servicing support and related facilities, along with data acquisition assets. The baseline launch system, the Peacekeeper SLV would also be a government furnished item. Although the actual cost estimates Boeing provided are proprietary, comparisons were made with other recent X-vehicle development programs, and the costs were found to be reasonable.

Boeing developed a notional organizational structure including four integrated product teams (IPTs), systems engineering, and business management / operational functions. Boeing also performed a risk-benefit analysis looking at testing at different flight conditions and assessing different goals. They determined that, although more challenging technically, testing at higher Mach numbers (up to Mach 15) and higher dynamic pressures (near 2,000 psf) provides the biggest payoff because those conditions are similar to those experienced by an operational system. In addition, un-powered testing at high Mach numbers, although potentially useful, do not provide nearly the benefit that powered tests do since a majority of the uncertainty is in the operation and performance of the propulsion system in flight. 


\begin{tabular}{|c|c|c|c|c|c|c|c|c|c|c|c|c|c|}
\hline \multirow[b]{2}{*}{ ID } & \multirow[b]{2}{*}{ mes } & \multirow[b]{2}{*}{ Task Name } & \multirow[b]{2}{*}{ Duration } & \multirow[b]{2}{*}{ Start } & \multirow[b]{2}{*}{ Finish } & 2004 & 2005 & 2006 & 2007 & 2008 & 2009 & 2010 & 2011 \\
\hline & & & & & & \begin{tabular}{|l|l|}
$\mathrm{H} 1$ & $\mathrm{H} 2$ \\
\end{tabular} & \begin{tabular}{|l|l|}
$\mathrm{H} 1$ & $\mathrm{H} 2$ \\
\end{tabular} & \begin{tabular}{|l|l|}
$\mathrm{H} 1$ & $\mathrm{H} 2$ \\
\end{tabular} & \begin{tabular}{|l|l|}
$\mathrm{H} 1$ & $\mathrm{H} 2$ \\
\end{tabular} & \begin{tabular}{|l|l|}
$\mathrm{H} 1$ & $\mathrm{H} 2$ \\
\end{tabular} & \begin{tabular}{|l|l|}
$\mathrm{H} 1$ & $\mathrm{H} 2$ \\
\end{tabular} & \begin{tabular}{|l|l|}
$\mathrm{H} 1$ & $\mathrm{H} 2$ \\
\end{tabular} & \begin{tabular}{l|l|}
$\mathrm{H} 1$ & $\mathrm{H} 2$ \\
\end{tabular} \\
\hline 1 & 0 & Authority to Proceed & 0 days & Mon 10/4/04 & Mon 10/4/04 & & $10 / 4$ & & & & & & \\
\hline 2 & 10000 & Program Management & 1607 days & Mon 10/4/04 & Tue 11/30/10 & & & & & & & & \\
\hline 11 & 20000 & Systems Engineering & 1607 days & Mon 10/4/04 & Tue 11/30/10 & & & & & & & & \\
\hline 18 & 20000 & Vehic/e Desiqn, inteqration and Test & 1409 days? & Mon 10/4/04 & Thu 2/25/10 & & & & & & & & \\
\hline 98 & 24000 & Engine System Design, Integration \& Test & 1220 days? & Fri 10/1/04 & Thu 6/4/09 & & & & & & & & \\
\hline 138 & 60000 & Independent Verification \& Validation & 693 days & Tue 11/13/07 & Thu 7/8/10 & & & & & & & & \\
\hline 148 & 33000 & Shroud Design, Integration \& Test & 821 days & Fri 9/30/05 & Fri 11/21/08 & & & & & & & & \\
\hline 174 & 34000 & Adapter Design, Integration \& Test & 426 days & Fri 9/30/05 & Fri 5/18/07 & & & & & & & & \\
\hline 200 & 70000 & Flight Operations & 1476 days & Fri $4 / 8 / 05$ & Fri 12/3/10 & & & & & & & & \\
\hline 201 & 32000 & Booster Selection & 2 days & Fri $4 / 8,05$ & Mon $4 / 11,05$ & & & & & & & & \\
\hline 202 & 71000 & RSLP Support Negotiated & 30 days & Tue $4 / 12 / 05$ & Mon 5/23/05 & & & & & & & & \\
\hline 203 & 72000 & Range Support Negotiated (RSLP-VAFB) & 30 days & Fri 5/13/05 & Thu $6 / 23 / 05$ & & & & & & & & \\
\hline 204 & $\mathbf{x 1 0 0 0}$ & Required Hon-Program Activity & 360 days & Fri 6/24/05 & Thu 11/9/06 & & & & & & & & \\
\hline 211 & 70000 & Flight 1 Campaign & 438 days & Tue 4/3/07 & Thu 12/4/08 & & & & & & & & \\
\hline 252 & 9.6 & Flight 1 & 0 days & Tue $9 / 30 / 08$ & Tue $9 / 30 / 08$ & & & & & & 0 & & \\
\hline 253 & 70000 & Flight 2 Campaign & 286 days & Thu 10/30/08 & Thu 12/3/09 & & & & & & & & \\
\hline 287 & 9.8 & Flight 2 & 0 days & Tue $9 / 29,09$ & Tue $9 / 29,09$ & & & & & & & 9 & \\
\hline 288 & 70000 & Flight 3 Campaign & 286 days & Fri 10/30/09 & Fri 12/3/10 & & & & & & & & \\
\hline 321 & 9.10 & Flight 3 & 0 days & Wed $9 / 29 / 10$ & Wed $9 / 29 / 10$ & & & & & & & & $9 / 29$ \\
\hline
\end{tabular}

Figure 15.Top level program schedule used for program costing.

\section{Summary and Conclusions}

Designing a vehicle that can accelerate for 30 seconds at Mach 15 was found to be feasible. Risk areas were identified, many of which are related to the state of the boundary layer on the vehicle. These include TPS temperature issues on the vehicle forebody, as well as uncertainty in overall vehicle drag, which will affect vehicle acceleration. The structures team determined that the adapter should probably be attached to the vehicle at a bulkhead near the mid-section of the engine. This concept is different than previous experience (X-43A), and has a potential for binding during separation. The size of the research vehicle necessitates a significantly larger shroud than that used on the standard Peacekeeper, but preliminary analysis shows there should be no stability and control issues with the launcher. Additional issues were identified with existing flight termination systems due to the vehicle downrange and flight test conditions.

The baseline vehicle design presented here performs the mission as required. Acceleration is achieved over a 30 second powered test. Costs could be reduced by narrowing the vehicle (thus reducing its size), but acceleration margin would be sacrificed. It is recommended that, should the program proceed, program goals should be clearly stated, i.e. if acceleration is a requirement, the vehicle may have to grow in width (and costs would increase) to increase the probability of acceleration. If acceleration is merely a desire, but the requirement is to demonstrate engine operation, costs could be reduced by narrowing the vehicle. A cost-benefit analysis is also recommended to examine the impact of required test time on vehicle scale (and cost).

Ultimately, the largest risk to moving forward with the X-43D or any of the other hypersonic flight demonstrators shown on the hypersonics roadmap is funding. Early in 2004, the President announced his vision for the future of space exploration to be implemented by NASA. The President and the NASA Administrator made it clear that the majority of the funding for this new initiative will come from re-directing existing funding within agency. Since the announcement, many of NASA's current programs and projects have been reviewed for their relevancy to the new initiative, including all of the hypersonics related projects. Most of the hypersonics projects have been eliminated. The impact that the recent success of X-43A will have on future funding decisions is unclear at this time.

\section{Acknowledgments}

The authors would like to thank Vince Rausch and Charles McClinton of the NGLT Future Hypersonic Flight Demonstrators Office for initiating and supporting the X-43D study. Thanks also to members of the team in the Vehicle Analysis Branch and with Swales Aerospace at NASA Langley Research Center, as well as to members of the team from Boeing Phantom Works sites in St. Louis, Huntington Beach, and Canoga Park. The 12 month study was a team effort and could not have been accomplished without the hard work of each member 


\section{References}

\footnotetext{
${ }^{i}$ McClinton, C.R., Hunt, J.L, Ricketts, R.H., NASA Langley Research Center; Reukaur, P., NASA Dryden Flight Research Center; and Peddie, C.L., NASA Glenn Research Center; "Airbreathing Hypersonic Technology Vision Vehicle and Development Dreams”, AIAA 99-4978, November 1999.

ii Access to Space Study: Summary Report; Office of Space Systems Development, NASA Headquarters, Jan. 1994.

iii Hunt, J.L., Petley, D.H., Moses, P.L., Martin, J.G., Ferlemann, S.M., Leonard, C.P., Pegg, R.J., Robinson, J.S., Taylor, L.W., and Vause, R.F.; NASA Langley Research Center, and Pinckney, S.Z., and Bouchard, K.A., Swales Aerospace, Hampton, VA; "Airbreathing Launch Vehicle Study"; presented at the $50^{\text {th }}$ JANNAF Propulsion Meeting, July 11-13, 2001, Salt Lake City, Utah.

iv McClinton, C.R., Sitz, J.R., “Hyper-X: Bridge to the Hypersonic Century”, 36 ${ }^{\text {th }}$ JANNAF CS/PSHS/APS Joint Meeting, Cocoa Beach, FL, October 1999.

iv Pinckney, S.Z. and Walton, J.T., "Program SRGULL: An Advanced Engineering Model for the Prediction of Airframe-Integrated Subsonic/Supersonic Hydrogen Combustion Ramjet Cycle Performance”, NASP TM-1120, January 1991.

v Pinckney, S.Z. and Walton, J.T., "Program SRGULL: An Advanced Engineering Model for the Prediction of Airframe-Integrated Subsonic/Supersonic Hydrogen Combustion Ramjet Cycle Performance”, NASP TM-1120, January 1991.

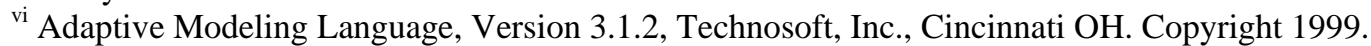

${ }^{\text {vii }}$ Ferlemann, S.M., Kamhawi, H., and Storch, A.M.; "Ramjet/Scramjet Engine Design and Analysis in the Collaborative Hypersonic Airbreathing Vehicle Environment (COHAVE)”; $52^{\text {nd }}$ JANNAF Propulsion Conference, May 2004.

viii Moses, P.L., Ferlemann, S.M., Leonard, C.P., Vause, R.F., and Pinckney, S.Z., FDC/NYMA Inc, Hampton VA; Robinson, J.S., Taylor, L.W., Martin, J.G., Hunt, J.L., and Petley, D.H.; NASA Langley Research Center; “Design and Development of an Airbreathing Launch Vehicle with Turbine-Based Low-Speed Propulsion and Dual Mode Ramjet/Scramjet High-Speed Propulsion”, 36 ${ }^{\text {th }}$ JANNAF CS/PSHS/APS Joint Meeting, Cocoa Beach, FL, October 1999.

${ }^{\text {ix }}$ Frink N.T., Tetrahedral Unstructured Navier-Frink N.T., “Tetrahedral Unstructured Navier-Stokes Method for Turbulent Flows”, AIAA Journal, Vol. 36, No. 11, pp. 1975-1982, November 1998.
} 